\title{
EL COVID-19 EN AMÉRICA LATINA: SITUACIÓN Y DESAFÍOS DEL SISTEMA INTERNACIONAL ${ }^{1}$
}

\author{
COVID-19 IN LATIN AMERICA: SITUATION AND CHALLENGES OF THE \\ INTERNATIONAL SYSTEM
}

Por José Antonio Saavedra Calderón (*)

\begin{abstract}
RESUMEN: El autor aborda la aparición de la COVID-19 desde el momento de la notificación emitida por China a finales de diciembre de 2019 a la Oficina Regional de la OMS en Wuhan, en la que se daba cuenta del desarrollo del virus y de las primeras medidas adoptadas, hasta el momento en que llegó a la región de América Latina a finales de febrero de 2020. De esta manera se explica el acuerdo entre profesores de Derecho Internacional y Relaciones Internacionales de varias universidades de América Latina, y la propuesta conjunta de discutir sobre Derechos Humanos, Migración, Medio Ambiente, Soberanía, Naciones Unidas, Inversiones y Organizaciones Internacionales.
\end{abstract}

PALABRAS CLAVES: COVID-19 - Derecho Internacional - Relaciones Internacionales - Naciones Unidas -Organizaciones Internacionales

\begin{abstract}
ABSTRAC: The author addresses the appearance of COVID-19 from the moment of the notification issued by China in late December 2019 to the Region Office of the WHO in Wuhan, which accounted for the development of the virus and first actions taken, until the moment when it reached the Latin American region in late February 2020. In this manner it explains the agreement between professors of International Law and International Relations from various universities in Latin America, and the joint proposal to discuss Human Rights, Migration, Environment, Sovereignty, United Nations, Investment and International Organizations.
\end{abstract}

KEY WORDS: COVID-19 - International Law - International Relations - United Nations International Organizations

\footnotetext{
${ }^{1}$ Artículo recibido el 5 de mayo de 2020 y aprobado para su publicación el 7 de junio de 2020.

Parte del contenido del artículo fue presentado en marco del Conversatorio Internacional "COVID 19 en América Latina: Situación y desafíos del Derecho Internacional", organizada por la Universidad San Ignacio de Loyola (Perú) el 11 de abril de 2020.

(*) Abogado, docente del curso de Política Internacional Latinoamericana y Política Internacional Peruana en la Universidad San Ignacio de Loyola, Miembro Asociado de la Sociedad Peruana de Derecho Internacional, Miembro de la Sociedad de Legislación Comparada, sede en Paris; Director Ejecutivo del Instituto Peruano de Derecho Comparado y Director Ejecutivo del Instituto Peruano de Derecho Registral; ha sido presidente de la Comisión Consultiva de Derecho Internacional Público del CAL, docente de los cursos de Derecho Internacional Público, Derecho Internacional Privado, Mediación, Conciliación y Arbitraje en la Universidad Inca Garcilaso de la Vega; ha sido Director Académico y Decano(i) de la Facultad de Derecho, Ciencia Política y Relaciones Internacionales de la Universidad Tecnológica del Perú; ha sido Agregado para Asuntos Legales y Jurisdiccionales del Ministerio de Relaciones Exteriores del Perú en el Reino de los Países Bajos y en el Consulado General del Perú en Zurich - Suiza, 2002 -2005. Tiene estudios equivalentes de maestría, Universidad de Paris 2, PantheónAssas - Francia, Estudios de postgrado de Derecho Comparado, Universidad de Paris 2, Pantheón-Assas Francia, Estudios de doctorado, Complutense de Madrid - España y actualmente en la Universidad Nacional Mayor de San Marcos, Lima, Perú.
} 


\section{(c) $(1)(2)$}

Artículo publicado bajo Licencia Creative Commons Atribución-No Comercial-Sin Derivar. (C) Universidad Católica de Córdoba

DOI http://dx.doi.org/10.22529/cdp.2020(8)03 


\section{EL COVID-19 EN AMÉRICA LATINA: SITUACIÓN Y DESAFÍOS DEL SISTEMA INTERNACIONAL}

El 31 de diciembre del año 2019 se informó a la Oficina Regional de la Organización Mundial de la Salud (OMS) en China la existencia de varios casos de neumonía de origen desconocido en la ciudad de Wuhan, provincia de Hubei ${ }^{2}$, contagiados que al día 03 de enero llegaban a 44 personas; días después un Comunicado de Prensa de la OMS daba cuenta de un caso en Tailandia en el cual se afirmaba que no se trataba de un "suceso inesperado", se ratificaba “la importancia del control y la preparación ..." y se daban orientaciones en la manera cómo actuar, todo esto gracias a que China había secuenciado los genes del virus lo que permitiría mejorar los diagnósticos ${ }^{3}$.

A finales del mes de enero del presente año tuvo lugar la reunión de alto nivel entre el Director General de la OMS, Dr. Tedros Adhanom Ghebreyesus y el Presidente de la República Popular China, Sr. Xi Jinping, sobre el brote del nuevo coronavirus nCov-2019; en la mencionada sesión las autoridades chinas se comprometieron a hacer los mejores esfuerzos y cooperación para enfrentar a un virus que en esos momentos llegaba a más de 4500 contagiados en el mundo, por su lado la OMS convocaría nuevamente a los miembros del Comité de Emergencias del Reglamento Sanitario Internacional ${ }^{4}$.

En el mes de febrero la OMS anunciaba un plan de preparación y respuesta a nivel mundial en un periodo entre febrero y abril; asimismo, expresaba la necesidad de fondos para preparar a los países más vulnerables en sus sistemas de salud teniendo en cuenta por un lado que el riesgo era muy elevado en China y por otro lado, que el riesgo era menor a nivel regional, además se anunciaba un Foro Mundial para impulsar las medidas a nivel internacional. Durante este tiempo 25 países ya habían confirmado la presencia del coronavirus, China tenía 25 mil infectados aproximadamente.

Desde esos días, la OMS continuó con una serie de acuerdos para acelerar la búsqueda de pruebas de diagnóstico en favor de los países con pocos recursos, igualmente celebró foros entre científicos, investigadores y financistas como el GloPID-R (Global Research Collaboration for

\footnotetext{
${ }^{2}$ Comunicado de Prensa de la OMS, información oficial tomada del vínculo: https://www.who.int/csr/don/05january-2020-pneumonia-of-unkown-cause-china/es/

3 A la fecha no se sabe a ciencia cierta la ciudad de origen de la pandemia en China aunque todo apunta a la ciudad de Wuhan, pero lo que si se conocía era el peligro y rapidez. Información oficial tomada del vínculo: https://www.who.int/es/news-room/detail/13-01-2020-who-statement-on-novel-coronavirus-in-thailand

4 Tal como se desprende del siguiente comunicado: https://www.who.int/es/news-room/detail/28-01-2020$\underline{\text { who-china-leaders-discuss-next-steps-in-battle-against-coronavirus-outbreak }}$
} 


\section{EL COVID-19 EN AMÉRICA LATINA: SITUACIÓN Y DESAFÍOS DEL SISTEMA INTERNACIONAL}

Infectious Disease Preparedness; así como, otros encuentros con la presencia de expertos de Alemania, Estados Unidos, Canadá, etc. Por su parte las Naciones Unidas dispuso dinero del Fondo Central para la Acción en casos de Emergencia, mientras tanto los casos en Irán, Italia, España y Suiza, entre otros, aumentaban desmesuradamente.

Así llegamos al mes marzo, el COVID-19 ya había sido considerado una Emergencia de Salud Pública de Importancia Internacional-(ESPII) conforme al Reglamento Sanitario Internacional, y el día 11 la OMS, teniendo en cuenta el peligro y la propagación, estableció que las características de una pandemia se habían cumplido. Mientras tanto, en nuestra región el virus había llegado desde finales de febrero a Brasil, México y Ecuador, y a principios de marzo en República Dominicana, Chile, Argentina, Colombia, Costa Rica y Perú en ese orden, es decir antes de ser considerada una pandemia.

El rápido aumento de infectados y las medidas adoptadas por los gobiernos en nuestra región han tenido efectos en la vida de todos, uno de ellos en la enseñanza universitaria que pasó de la noche a la mañana a ser una educación no presencial mediante la utilización de medios tecnológicos para el dictado de clases y evaluación. Este cambio en la enseñanza presencial encontró a algunos profesores organizados y especializados de distintas universidades de la región con las mismas incertidumbres y reflexiones acerca del COVID-19.

De esta manera, conjuntamente con los profesores Christian Sommer de la Universidad Católica de Córdoba en Argentina, Laura García de la Universidad del Rosario en Colombia, Marisol Anglés Hernández del Instituto de Investigaciones de la UNAM- México; Alberto Moreira de la Universidad Nacional de Mar del Plata, Argentina, Wagner Menezes de la Universidad de Sao Paulo, Brasil; Ángel V. Horna y el suscrito José Antonio Saavedra Calderón, ambos de la Universidad San Ignacio de Loyola, iniciamos la idea de un debate abierto sobre el derecho internacional y las relaciones internacionales bajo la forma de un webinar.

Así, con el auspicio de la Facultad de Derecho y la Carrera de Relaciones Internacionales de la Universidad San Ignacio de Loyola, Perú se materializa la idea de un grupo de profesores de exponer vía Zoom y Facebook live un webinar sobre la Situación y desafíos del sistema internacional frente a la COVID-19, el mismo que tuvo lugar el 11 de abril del presente año. 


\section{EL COVID-19 EN AMÉRICA LATINA: SITUACIÓN Y DESAFÍOS DEL SISTEMA INTERNACIONAL}

El webinar tuvo como primer tema la "Soberanía y Cooperación Internacional. Reflejos del Derecho Internacional frente al desafío del COVID-19” a cargo del Doctor Alberto Moreira quien abordó el impacto del COVID-19 en un mundo globalizado mencionando la Resolución de la Asamblea General de la ONU del pasado 03 de abril que hizo un llamado a la solidaridad mundial calificando a la pandemia como una amenaza así como la necesidad de una respuesta bajo el multilateralismo.

El profesor Moreira trató la relación del derecho internacional con la soberanía y la cooperación internacional, reconociendo a aquellos que critican la insensatez de la misma y que postulan la necesidad de una Constitución de la Tierra, añadiendo además, que la soberanía es un mal endémico del derecho internacional, es un principio básico y así muchos hablen de su superación es el problema en realidad.

Según Moreira vivimos una época de derecho internacional contemporáneo que va más allá de los intereses de los estados, por ejemplo en Derechos Humanos y el Medio Ambiente por este motivo en el caso del COVID-19 será necesario tomar medidas coherentes, porque la práctica estatal demuestra una plena vigencia de la soberania, la summa potesta, pero de manera desarticulada debido a que en algunos casos se ha limitado derechos de extranjeros y en otros, se ha vulnerado la compra de insumos de ciertos países exacerbando nacionalismos y xenofobia.

Si bien, la Cooperación internacional es una expresión de la soberanía a veces se queda atrapada en la búsqueda de intereses comunes por razones geoplíticas entre los estados, por eso vemos respuestas que no son similares en los organismos internacionales, pero atribuirle a la soberanía toda la responsabilidad es desconocer cómo funciona el sistema internacional, la soberanía tiene y muestra una renovada vigencia, pero tiene límites y eso es parte de la realidad internacional, no obstante debemos poner énfasis en lo multilateral y la cooperación internacional.

El segundo tema "Los desafíos de las Naciones Unidas frente al COVID-19", estuvo a cargo del Doctor Ángel V. Horna quien debido a su experiencia en la Misión Permanente del Perú ante las Naciones Unidas postula que estamos ante la mayor prueba que el mundo ha enfrentado desde la creación de la ONU para tal efecto propone 7 desafíos: 1. Renovar el multilateralismo, 2. Lograr una respuesta coordinada del sistema de las Naciones Unidas : Sin 


\section{EL COVID-19 EN AMÉRICA LATINA: SITUACIÓN Y DESAFÍOS DEL SISTEMA INTERNACIONAL}

desconocer el trabajo realizado por la OMS, no ha habido una correcta recepción en el sistema internacional, 3. Superar la parálisis del Consejo de Seguridad: se debe mantener la paz, las seguridades internacionales y la protección de los derechos humanos, 4. Prevenir el impacto de la pandemia mediante una acción humanitaria: especialmente los países afectados por otras circunstancias son más vulnerables y es necesario velar por ellos, 5. Garantizar el pleno respeto a los derechos humanos: se busca mantener el respeto en los casos de estados o situaciones de emergencia, 6. El rol de la ONU en la solución de controversias: especialmente el rol de la Corte Internacional de Justicia, y finalmente 7. Considerar posibles iniciativas para la esperada reforma de las Naciones Unidas.

Asimismo, Horna entiende que el COVID-19 es una oportunidad para buscar una cuarentena a los conflictos armados, superar las discrepancias entre los Miembros Permanentes del Consejo de Seguridad y favorecer las acciones humanitarias, además, velar por los derechos humanos en tiempos de emergencia sanitaria y lamenta que esta situación de pandemia postergue los Objetivos del Desarrollo Sostenible.

El tercer tema "el derecho internacional contemporáneo y los desafíos del COVID-19 es desarrrollado por el Doctor Wagner Menezes quien entiende que existen liderazgos con diferencias ideológicas que afectan a los derechos humanos, y que ante la pandemia no estamos precisamente ante una guerra por eso no se justifica la limitación de los derechos fundamentales, todo lo contrario existe una necesidad de solidaridad, de implementación de políticas éticas o de alternativas como la creación de una Organización Internacional de la Ciencia.

Enfrentar este desafío requiere de cambios porque hay hechos concretos como el límite al acceso a los medicamentos o la politización de la nacionalidad del virus, discursos antiglobalización o teorías de conspiraciones y no tenemos acciones concretas, sino insensibilidad por parte de los líderes políticos, esto demostraría que la OMS no cumplió, que la pandemia se le fue de control mientras que en la región tenemos dependencia en muchos aspectos de la salud.

Finalmente, el profesor Menezes está en contra de la constitucionalización del derecho internacional porque considera que es una forma centralizar los problemas y eso es justamente lo que no se necesita, y que una constitución no va a solucionar las pandemias, que debe 


\section{EL COVID-19 EN AMÉRICA LATINA: SITUACIÓN Y DESAFÍOS DEL SISTEMA INTERNACIONAL}

prevalecer el conocimiento científico, la importancia de la ciencia y reitera la creación de una Organización Internacional de la Ciencia.

El cuarto tema es el futuro de los contratos internacionales afectados por el COVID-19 bajo la responsabildiad de la Doctora Laura García, quien entiende que la pandemia está perturbando las relaciones comerciales por ejemplo, en el caso de las inversiones donde se plantean hipótesis, por ejemplo si los contratos pueden dejar de cumplirse sin tener consecuencias como indemnizaciones o perjuicios en la medida que estamos ante hechos no previstos y cuya causa no se puede atribuir a las partes.

En este sentido, vivimos situaciones excepcionales de orden público para proteger la salud pública debido a motivos de fuerza mayor, de estado de necesidad y peligro.

El quinto tema tuvo la reflexión de la profesora Marisol Anglés Hernández sobre la "Crisis climática y el Covid -19” en la medida que esto tiene efectos en los derechos fundamentales como el aire, agua, alimentos, temperatura ,etc, así como los cambios de temperatura que afectan la supervivencia del virus. Requerimos un enfoque “One Health" de interdependencia ecológica, de riesgos de los ecosistemas y las interacciones entre especies, tanto animales, vegetales e incluido el ser humano.

Una de las razones de la aparición de enfermedades son los factores propios de la globalización, tales como el intercambio comercial, movilidad internacional y el cambio climático. En este sentido, el Acuerdo del Paris (2015), sostiene la profesora, demostró la insuficiencia de las propuestas en cuanto a la reducción de dióxido de carbono.

El sexto tema, tuvo como expositor al Doctor Christian Sommer sobre "movilidad humana derecho de retorno y estándares internacionales en el contexto del COVID-19”, quien manifiesta dos situaciones: las migraciones irregulares y el derecho de retorno.

El profesor Sommer sostiene que la migración irregular genera vulnerabilidad especialmente en los momentos de la pandemia lo que impacta en el respeto o atención de derechos esenciales, sobretodo en caso de menores y ancianos, y en este sentido el Estado no puede discriminar ningún tipo de asistencia o acceso al trabajo, existiendo en el caso particular dos opiniones consultivas en el contexto de la CIDH.

Hay particularidades, por ejemplo en los casos de xenofobia, ser extranjero se etiqueta como portador del virus y el cierre de las fronteras agrava la situación, por eso es necesario adoptar 


\section{EL COVID-19 EN AMÉRICA LATINA: SITUACIÓN Y DESAFÍOS DEL SISTEMA INTERNACIONAL}

medios idóneos para evitar estas situaciones, por ejemplo tener en cuenta las acciones de la CIDH y de la OEA.

Otro estándar es la debida diligencia para conocer si los estados cumplen sus obligaciones como por ejemplo en el caso del derecho al retorno, y eso significa que hay ciudadanos que no pueden regresar a sus países y aquí tenemos diferentes tratos, siendo uno de ellos el derecho de entrar a un país y vemos que en algunos casos el Estado ha realizado el retorno, en consecuencia, tendría que justificar porque en otros casos no, de la mano con el test de la vulnerabilidad.

Sobre las normas de emergencia que se han tomado en varios países, el profesor Sommer considera importante el sentido y lo razonable en estas situaciones para definir cuáles son los límites. En concreto, los aportes del Derecho Internacional en los casos de migraciones y de retorno en el contexto del COVID-19.

Como podremos apreciar los efectos del COVID-19 en el derecho internacional y las relaciones internacionales plantean una serie de posiblidades en medio de múltiples interrogantes en cada una de las especialiades desarrolladas en el webinar, apostándose en muchos casos por la esperanza de cambios en el sistema de las Naciones Unidas y en el ordenamiento jurídico internacional.

Lamentablemente, el tiempo no ha sido suficiente para reflexionar acerca de la OEA, sobre la Guía Práctica de Repuestas Inclusivas y con Enfoque de Derechos recientemente publicada, o la Sala de Coordinación y Respuesta Oportuna impulsada por la CIDH (SACROI), así como las alertas en favor de los pueblos indígenas; sin olvidar tampoco a la Organización Panamericana de la Salud que a través de sus guías técnicas sigue la evolución de la pandemia y busca donantes.

Finalmente, mientras en la mayoría de nuestros países cumplimos medidas de distanciamiento físico y aislamiento social estamos a la espera que los estados realicen los mejores esfuerzos para cumplir el Reglamento Sanitario Internacional de la OMS y su implementación al momento de emitir sus decisiones internas; igualmente se espera la consolidación de algunas alternativas como por ejemplo la creación de un Comité Científico o de expertos, independientes de los estados para que puedan proponer soluciones no solamente a esta 


\section{EL COVID-19 EN AMÉRICA LATINA: SITUACIÓN Y DESAFÍOS DEL SISTEMA INTERNACIONAL}

pandemia sino a todas aquellas que desde hace años vienen siendo anunciadas en diferentes fueros. 